\title{
PRINCIPAIS GEOBARÔMETROS UTILIZADOS EM GRANULITOS: ANÁLISE DOS RESUITADOS DE UM EXEMPLO DO SUL DA BAHIA - BRASIL
}

\author{
JOHILDO SALOMÃO FIGUEIREDO BARBOSA*
}

\begin{abstract}
MAIN GEOBAROMETERS USED ON GRANULITES: ANALYSIS OF RESULTS OF AN EXAMPLE FROM SOUTHERN BAHIA - BRAZIL. A critical evaluation of the most usual geobarometer schemes on the granulite region of Southern Bahia, Brazil, an area of remarkably uniform metamorphic conditions, revealed that: $\mathbf{i}$. the Wood \& Banno and Wood geobarometers are not applicable to the area (highly dispersed results) due to their strong dependence on the bulk chemical composition of the samples (particularly with respect to alumina saturation; ii. the Ellis and Bohlen et al. geobarometers, although producing better values than the previous ones, still slow of signs strong dependence on temperature and composition; and iii. the Newton \& Perkins and especially the Wells geobarometers which allow for better consideration of actual garnet, produced the geologically more meaningful pressure values.
\end{abstract}

INTRODUÇÃO A introdução dos métodos de resoluções termodinâmicas em Petrologia teve notadamente, por conseqüência, a definição de numerosos termômetros e barômetros.

A determinação das temperaturas e das pressōes pode evidentemente introduzir progressos essenciais na compreensão dos mecanismos da petrogênese. Cada termômetro ou barômetro exprime a dependência da temperatura ou da pressão de um certo equilibrio entre as fases minerais. Todos foram calibrados com base em dados experimentais.

Sabe-se que i. o equilíbrio nâo foi sempre perfeitamente controlado em todos os trabalhos experimentais publicados e ii. os dados experimentais são estabelecidos, a maior parte do tempo, em sistemas de composiçöes químicas muito simples enquanto os sistemas naturais são complexos e o número de elementos que podem entrar de modo apreciável nas soluçōes sólidas silicatadas, por exemplo, é considerável.

A existência de problemas na calibragem dos geotermômetros e geobarômetros deve incitar o geólogo à prudência. É entâo natural que se utilizem dos meios disponíveis para testar os geotermômetros que são propostos antes de arriscar a utilização dos valores de temperaturas ou de pressōes, fornecidos por estas formulas, nos mecanismos da petrologia ou da geodinâmica.

$\mathrm{O}$ teste geológico aqui proposto parte do princípio de que, num dado instante, as variações de temperatura e pressão são limitadas e sobretudo regulares na escala quilométrica. Em relação às temperaturas, considera-se a presença de fontes de calor somente muito localizadas e com fraco desequilíbrio de temperatura com suas encaixantes. No que diz respeito às pressōes sólidas, admite-se que elas não se afastam de modo significativo da pressão litostática, pelo menos quando as discussōes se limitam aos terrenos formados a altas temperaturas, na presença de água em quantidades desprezíveis, e, excluindo os períodos de deformaçőes ativas, que também pela mesma razão devem representar somente episódios extremamente limitados no tempo.

A dificuldade para aplicar esse teste reside na necessidade de comparar as associaçöes minerais estritamente contemporâneas. Desta necessidade procedem as discussões necessárias para um exame dos fenômenos das reaçôes metamórficas, dos equilíbrios minerais, das paragêneses superpostas e das retrometamorfoses.

Na prática atual, os geotermômetros são menos problemáticos que os geobarômetros. Os termômetros que dâo resultados muito incoerentes não foram considerados. $\mathrm{Na}$ estimativa das temperaturas foram usados só os mais utilizados e confiáveis, embora com uma imprecisão da ordem de $10 \%$ em relação à temperatura absoluta.

O objetivo deste trabalho é examinar criticamente os valo- res obtidos para as pressőes no caso das rochas granulíticas, testando a confiabilidade dos métodos geobarométricos mais utilizados atualmente. Verificar-se-á que a maioria desses métodos conduzem a resultados incoerentes e quase sempre fornecem valores exageradamente elevados.

GEOBARÔMETROS UTILIZADOS Neste trabalho, os geobarômetros mais utilizados foram testados em rochas básicas granulitizadas e em quartzitos com granada-ortopiroxênio, que ocorrem na regiẩo granulítica do sul da Bahia (Fig. 1). Nas rochas granulitizadas, os geobarômetros usuais são fundamentados nos equilíbrios entre minerais nas seguintes assembléias: ortopiroxênio-granada-plagioclásio-quartzo e clinopiroxênio-granada-plagioclásio-quartzo. Nos quartzitos granulitizados, eles se baseiam nos equilíbrios entre ortopiroxênio-granada-quartzo.

No caso da associação ortopiroxênio-granada, Wood \& Banno (1973) e Wood (1974) estudaram a reação

$$
\frac{\mathrm{Mg}_{2} \mathrm{Si}_{2} \mathrm{O}_{6}+\mathrm{Mg} \mathrm{Al}_{2} \mathrm{SlO}_{6}}{\text { Opx solução sollida }} \leftarrow \frac{\mathrm{Mg}_{3} \mathrm{Al}_{2} \mathrm{Si}_{3} \mathrm{O}_{12}}{\text { Gt soluçăo sollida }}
$$

e propuseram duas fórmulas (Tab. 1) baseadas nas substituiçồes dos cátions $\mathrm{Fe}^{2}+, \mathrm{Mg}^{2}+\mathrm{e} \mathrm{AlVI}^{2}$ entre essas duas fases supostas em equilíbrio. A discrepância por diversos autores (Ellis 1980, Bohlen et al. 1983, Essene 1983), embora sejam ainda utilizados atualmente. Eles apresentam o grande defeito de considerar as granadas como soluções sólidas ideais.

Dois outros métodos barômetricos muito utilizados nos granulitos são os de Wells (1979) e de Newton \& Perkins (1982). Esses autores realizaram uma modelização termodinâmica da reação contínua

$$
\frac{\mathrm{Mg}_{2} \mathrm{Si}_{2} \mathrm{O}_{6}}{\text { Opx s.s. }}+\frac{\mathrm{CaAl}_{2} \mathrm{Si}_{2} \mathrm{O}_{8}}{\text { Plag. s.s. }} \leftarrow \frac{2 / 3 \mathrm{Mg}_{3} \mathrm{Al}_{2} \mathrm{Si}_{3} \mathrm{O}_{12}+1 / 3 \mathrm{Ca}_{3} \mathrm{Al}_{2} \mathrm{Si}_{3} \mathrm{O}_{12}}{\text { Gi. s.s. }}+\frac{\mathrm{SiO}_{2}}{\text { Ozo }}
$$

o que permitiu estabelecer fórmulas (Tab. 1) para o cálculo das pressões de equilíbrio dessas fases minerais durante o metamorfismo de alto grau. Contrariamente aos autores precedentes, Wells (op. cit.) e Newton \& Perkins (op. cit.) fazem intervir, em suas fórmulas, os coeficientes de atividade das granadas e dos plagioclásios das diferentes "moléculas" que participam da reação (2). Constatar-se-á mais adiante que este procedimento se justifica, pois esses geobarômetros fornecem resultados mais coerentes.

Baseando-se na grande variação de volume e na pequena variação de entropia da reação 


$$
\frac{\mathrm{Ca} \mathrm{Al}_{2} \mathrm{Si}_{2} \mathrm{O}_{8}}{\text { An no plag }} \leftrightarrows \frac{\mathrm{Ca} \mathrm{Al}_{2} \mathrm{SiO}_{6}}{\text { CaTs no Cpx }}+\mathrm{SiO}_{2}
$$

Ellis (1980) estabeleceu um outro geobarômetro, clinopiroxênio-plagioclásio (Tab. 1), igualmente útil para aplicação nos granulitos básicos.

REGIÃO GRANULÍTICA DO SUL DA BAHIA Descrição Geral Os barômetros descritos anteriormente foram testados na região granulítica do sul da Bahia, que pode ser considerada com uma das mais vastas áreas granulíticas de idade arqueana e/ou proterozóica que aflora no mundo (Fig. 1).

De oeste para leste, esta regiâo mostra diferenças claras quanto à tectônica, à petrologia e ao quimismo das rochas existentes. Isso justificou a distinção de três domínios geológicos (Barbosa 1986):

DOMÍNIO JEQUIÉ-MUTUÍPE - Situado na parte ocidental, é comparável ao Complexo Jequié (Cordani 1973) e litologicamente representado por:

a) rochas plutônicas enderbíticas, charno-enderbíticas e charnockíticas deformadas e reequilibradas na fácies granulito. São consideradas ou como fazendo parte do embasamento antigo da regiäo, ou como intrusões precoces que ocorreram

Tabela 1 - Fórmulas termodinâmicas utilizadas para os cálculos das pressões

\section{FÓRMULAS TERMODINÂMICAS}

Wood \& Banno (1973)

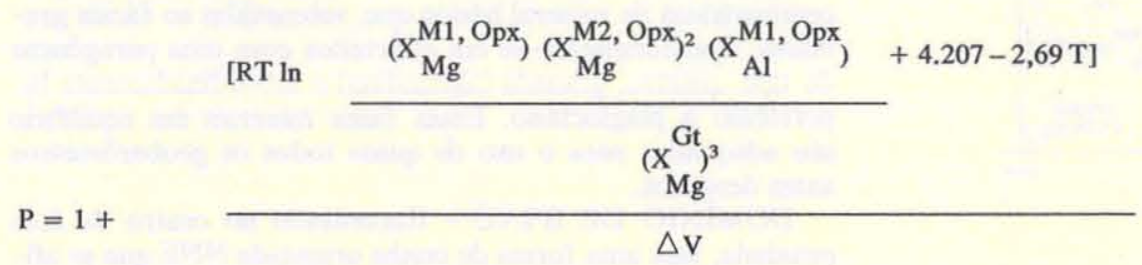

\section{Wood (1974)}

$\mathrm{P}=\mathrm{RT} \ln \frac{\left(\mathrm{X}_{\mathrm{Al}}^{\mathrm{M} 1}\right)\left(1-\mathrm{X}_{\mathrm{Al}}^{\mathrm{M} 1}\right)}{\left(1-\mathrm{X}_{\mathrm{Gr}}^{\mathrm{Gt}}\right)^{3}}+\frac{\mathrm{Fe}}{\Delta \mathrm{V}} \mathrm{Al}$ com C $=10.450 \mathrm{bar}$

Wells (1979)

$\mathrm{P}=1+3.300+6,26 \mathrm{~T}+\mathrm{RT} \ln \mathrm{K}_{\mathrm{A}}$

0,56771

Ellis (1980)

$\mathrm{P}=\frac{5.360+\mathrm{T}(2,98+1,98 \ln \mathrm{K})+12,86 \mathrm{XCaTs}(1-\mathrm{CaTs})-26,88[\mathrm{XCaTs}(1-\mathrm{X} \mathrm{CaTs})]^{2}-\mathrm{XAb} \times \mathrm{An}[967+715(\mathrm{XAb}-\mathrm{XAn})] ; \mathrm{K}=\mathrm{X}_{\mathrm{Cpx}}^{\mathrm{CaTs}}}{0,349}$

Newton \& Perkins (1982)

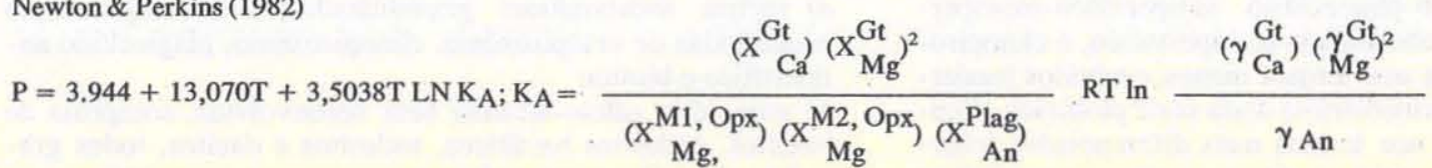

Bohlen et al. (1983)

Para estimar as pressōes utilizando este barômetro, ver a figura 7 no artigo de Bohlen et al. (1983)

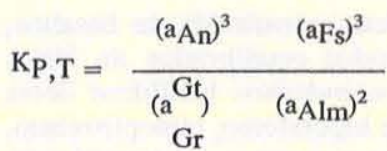



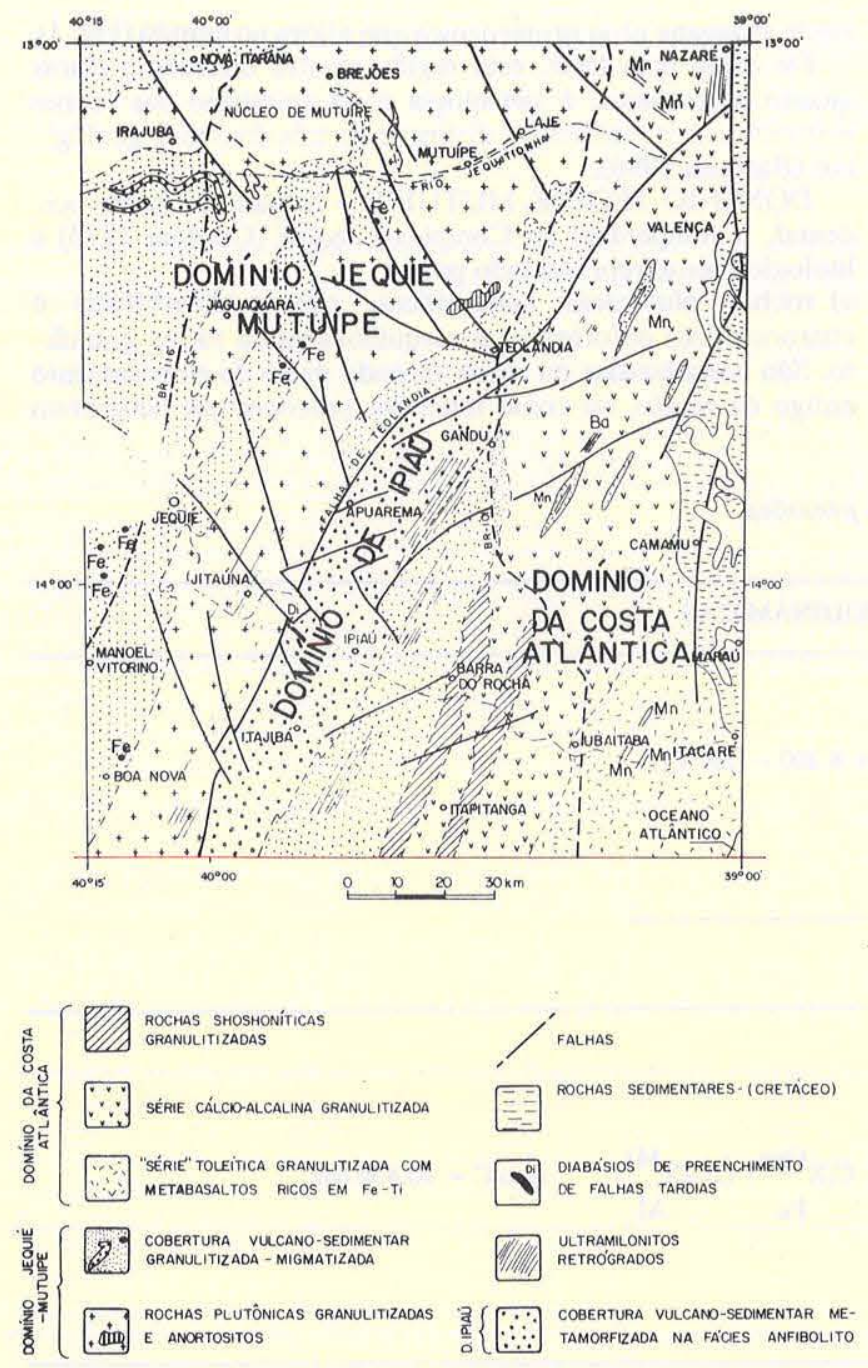

Figura 1 - Esboço geológico da regiäo granulítica do sul da Bahia (adaptado e simplificado de Barbosa 1986)

antes do pico do metamorfismo regional. Essas rochas são provavelmente co-magmáticas formadas a partir de um magma com tendência calcia-alcalina. São comparáveis às séries enderbíticas-charnockíticas arqueanas de Madras, Índia (Subramanian 1967, Weaver et al. 1978 apud Windley \& Naqvi 1978), e de Qianan-Habei, China (Wang Kaiyi et al. 1985). A paragênese metamórfica principal dessas rochas é composta de hiperstênio-clinopiroxênio-plagioclásio antipertítico-mesopertita-quartzo. Embora subordinado ao hiperstênio, o clinopiroxênio é mais abundante nos termos menos evoluídos (enderbitos ou granulitos intermediários) desta série plutônica, diminuindo em quantidade nos termos mais diferenciados (charnockitos ou granulitos ácidos). O plagioclásio antipertítico também tem o mesmo comportamento que o clinopiroxênio: é mais abundante nos enderbitos que nos charnockitos, estes mais ricos em mesopertita, microclina pertítica e quartzo. Associa-se localmente na paragênese principal dessas rochas à biotita vermelha e à hornblenda marrom, igualmente primárias. Vale salientar que a ausência de granadas as torna imprestáveis para a utilização de geobarômetros.

b) rochas supra-crustais, vulcano-sedimentares, constituídas de intercalações de níveis quartzo-feldspáticos com níveis de basaltos toleíticos, ambos granulitizados, e que na maior parte do Domínio Jequié-Mutuípe estão transformados e mistura- dos pela migmatização, metassomatose e anatexia em alto grau. Esses processos deram origem aos migmatitos granulíticos (resistatos básicos, "paleossomas" charnockíticas, neossomas) e remobilizados potássicos com ortopiroxênios (pegmatitos granulíticos). Ainda nessa seqüência supracrustal são encontradas, subordinadamente, calco-silicáticas, kinzigitos, rochas ultramáficas serpentinizadas, formações ferríferas bandadas e quartzitos com granada e ortopiroxênio que, em geral, resistiram aos processos de migmatização.

Os níveis de basaltos toleíticos granulitizados e os resistatos básicos dos migmatitos granulíticos (granulitos básicos) são formados essencialmente por hiperstênio, clinopiroxênio, hornblenda marrom esverdeada e sobretudo plagioclásio. Os níveis quartzo-feldspáticos e neossomas dos migmatitos granulíticos são constituídos principalmente de quartzo, mesopertita e microclina pertítica. Os "paleossomas" charnockíticos têm uma assembléia mineralógica semelhante aos charnockitos plutônicos reequilibrados na fácies granulito.

Sublinha-se nessas supra-crustais arqueanas a importância das prováveis camadas de cherts impuros com intercalações centímetricas de mineral básico que, submetidas ao fácies granulito, transformaram-se em quartzitos com uma paragênese do tipo quartzo, granada (almandina) e subordinadamente hiperstênio e plagioclásio. Essas fases minerais em equilíbrio são adequadas para o uso de quase todos os geobarômetros antes descritos.

DOMÍNIO DE IPIAÚ - Encontrado no centro da área estudada, tem uma forma de cunha orientada NNE que se afina em direção ao norte (Barbosa 1986). Suas rochas são praticamente as mesma supracrustais do Domínio Jequié-Mutuípe, porém elas se encontram metamorfizadas na fácies anfibolito de alto grau. A leste do Domínio de Ipiaú é possível verificar que essas rochas transicionam para a fácies granulito com o aparecimento de migmatitos granulíticos formados abaixo da isógrada da hornblenda e produzidos pelo metamorfismo granulítico progressivo.

Os níveis de anfibolitos, representantes dos basaltos toleíticos reequilibrados na fácies anfibolito, são constituídos essencialmente de plagioclásio e hornblenda, ocorrendo subordinadamente clinopiroxênio e quartzo. Os níveis quartzo-feldspáticos desse domínio, intercalados aos níveis de anfibolitos, são. constituídos principalmente de quartzo e microclina que, às vezes, é pertítica.

DOMÍNIO DA COSTA ATLÂNTICA - Localizado na parte oriental da área, é comparável ao Mobile Belt da costa Atlântica (Mascarenhas 1973, 1979) ou ao Bloco de Itabuna (Pedreira et al. 1975). Suas rochas são provavelmente também supracrustais mas, neste domínio, predominam rochas granulíticas de composição básica a intermediária. A petroquímica e a distribuição territorial dessas rochas permitem interpretar que os protolitos deste domínio, no conjunto, assemelham-se a litologias encontradas em arcos de ilhas recentes ou de margem continental ativa. Assim, foram identificadas:

a) rochas shoshoníticas granulitizadas, mineralogicamente constituídas de ortopiroxênio, clinopiroxênio, plagioclásio antipertítico e biotita;

b) uma série cálcio-alcalina bem desenvolvida, composta de basaltos, andesitos basálticos, andesitos e dacitos, todos granulitizados. Os metabasaltos possuem uma assembléia composta por hipestênio, clinopiroxênio e plagioclásio. Nos metandesitos, a quantidade de clinopiroxênio decresce, sendo quase inexistente nos metadácitos. Entretanto, a quantidade de plagioclásio nesses últimos é maior que nas outras rochas da série. Nesses granulitos, a biotita e a hornblenda primárias são raras;

c) uma "série" toleítica incompleta, constituída de basaltos, andesitos basálticos e riolitos, todos equilibrados na fácies granulito. Nos metabasaltos e metandesitos basálticos dessa "série", observa-se a presença de hiperstênio, clinopiroxênio, plagioclásio e granada, sendo raro o quartzo e a hornblenda. 
As granadas, primárias, encontram-se em processo de destruição, pois reagem com o clinopiroxênio, em presença do quartzo, produzindo uma segunda geração de ortopiroxênio e plagioclásio, ricos em anortita;

d) basaltos ricos em $\mathrm{Fe}-\mathrm{Ti}$, granulitizados, em geral associados a ocorrências de manganês (Toniatti \& Barbosa 1973, Valarelli et al. 1982), e que têm características químicas semelhantes a basaltos de paraplataforma. Nesses granulitos básicos, ricos em $\mathrm{Fe}-\mathrm{Ti}$, as fases minerais, grosso modo, são semelhantes aos metabasaltos e metandesitos basálticos da "série" toleítica, precedente, com a diferença, entretanto, de que eles são muito mais ricos em minerais opacos. Nesses metabasaltos ricos em $\mathrm{Fe}-\mathrm{Ti}$, verifica-se, ao redor do ortopiroxênio e de minerais opacos, numa matriz de plagioclásio rico em albita, coroas reacionais de granada de segunda geraçâo, em geral em associação simplectítica com o quartzo (reação 2).

Vale salientar aqui que, assim como os quartzitos granulíticos com granada e ortopiroxênio, os metabasaltos dos dois últimos grupos de rocha sâo úteis na estimativa de pressōes de cristalização, visto apresentarem paragêneses metamórficas Opx-Cpx-Gt-Plag-Qzo em equilíbrio e portanto adequadas para o uso dos geobarômetros freqüentemente utilizados em terrenos granulíticos.

Em relação à tectônica, toda a região granulítica do sul da Bahia foi fortemente deformada, no mínimo por três fases de deformação dúctil: a primeira, de dobras recumbentes de $\mathrm{E}$ para W com eixos N15E; a segunda, de dobras isoclinais, simétricas-assimétricas co-axial à primeira; $\mathrm{e}$, finalmente, a terceira fase, de dobras com pequena amplitude e grandes comprimentos de onda, todavia com eixos transversais às duas primeiras.

A etapa progressiva do metamorfismo da área atingiu seu clímax após a paralização das fases de deformaçôes mais importantes, reequilibrou as rochas plutônicas enderbíticas- charnockíticas e transformou em granulitos a maioria das rochas de cobertura. Escaparam da granulitização as litologias do Domínio de Ipiaú, que se encontram metamorfizadas na fácies anfibolito de alto grau (Barbosa 1986).

As temperaturas metamórficas que atuaram na fácies granulito foram variáveis ao longo da área, alcançando valores máximos de $880^{\circ} \mathrm{C}$ e mínimos de $730^{\circ} \mathrm{C}$, segundo os métodos geotermométricos de Wood \& Banno (op. cit.) e de Wells (1977), os mais utilizados e considerados relativamente bem confiáveis quando se trata de áreas granulíticas. As temperaturas máximas foram calculadas a partir de paragêneses comprovadamente equilibradas no pico do metamorfismo. As temperaturas mínimas, retrógradas, foram estimadas em lamelas de exsolução nos piroxênios ou utilizando-se duplas Opx-Cpx encontradas nos metabasaltos ricos em $\mathrm{Fe}-\mathrm{Ti}$, portadores de granada de segunda geração. As figuras 2 e 3 mostram, além do equilíbrio das duplas Opx-Cpx em diversas amostras de rochas recolhidas aleatoriamente em toda a área, também o abaixamento progressivo da temperatura no curso da evolução tardia do metamorfismo.

A etapa regressiva deste metamorfismo é identificada em algumas zonas restritas onde ocorrem ultramilonitos e milonitos. Nessas zonas, as rochas granulíticas foram reequilibradas na fácies anfibolito e xisto-verde. Todavia, na maioria dos granulitos da área, o retrometamorfismo é identificado por leves desequilíbrios das paragêneses metamórficas primárias, contemporâneos provavelmente ao levantamento epirogenético da região.

Resultado dos Cálculos de Pressão Para testar a eficácia dos barômetros descritos anteriormente, foram escolhidas cinco amostras de composições químicas diferentes mas com paragêneses contendo granada. Os pontos de amostragem sâo espaçados, na maioria dos casos de algumas centenas de

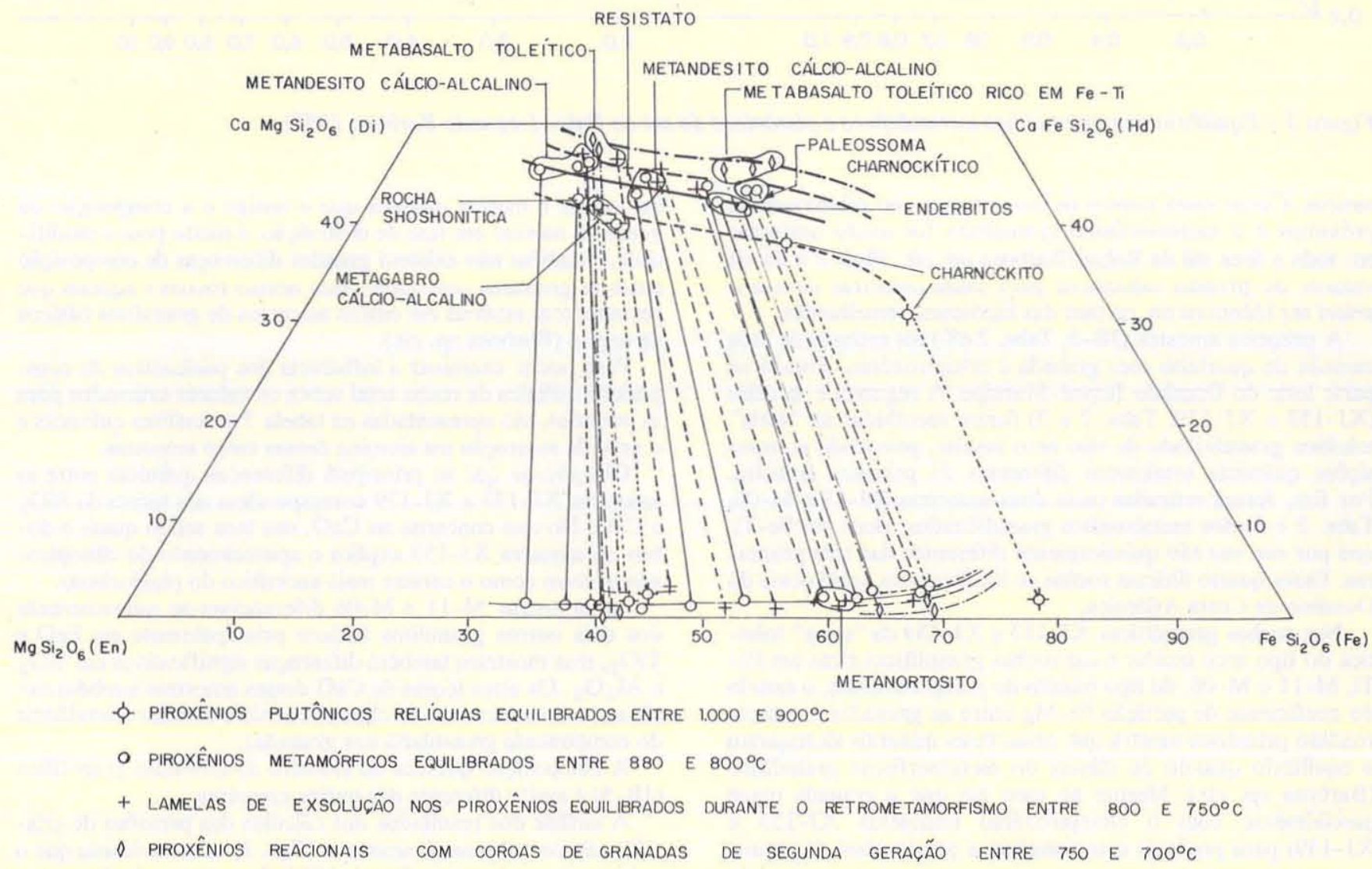

Figura 2 - Piroxênios metamórficos e plutônicos do sul da Bahia (segundo Barbosa 1986) 


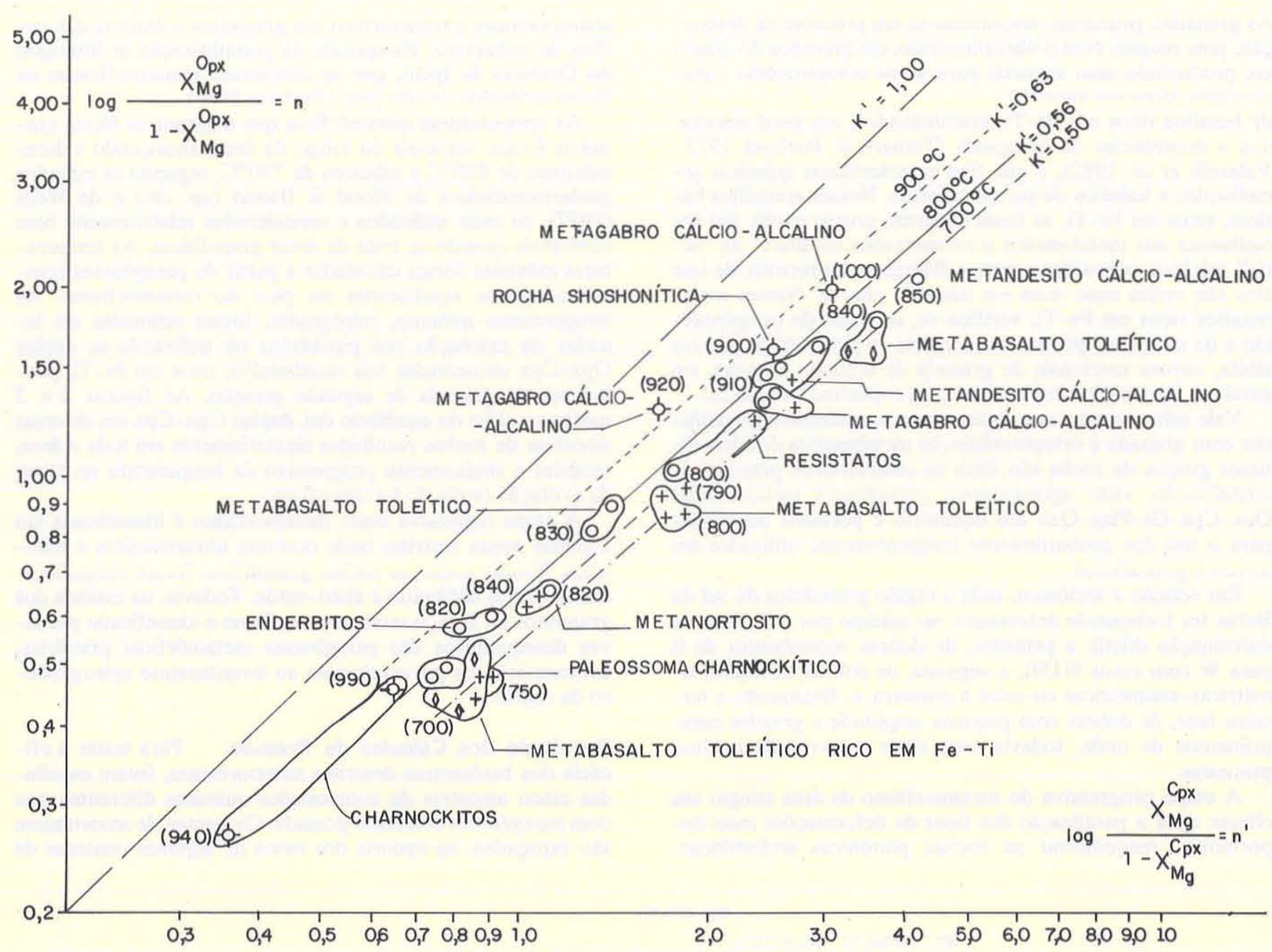

Figura 3 - Equilibrio entre piroxênios metamórficos e plutônicos do sul da Bahia (segundo Barbosa 1986)

metros. Como esses pontos de amostragem são relativamente próximos e o metamorfismo granulítico foi muito uniforme em toda a área sul da Bahia (Barbosa op. cit., Figs. 2 e 3), os valores de pressão calculados para essas amostras devem $a$ priori ser idênticos ou, na pior das hipóteses, semelhantes.

A primeira amostra (JB-5, Tabs. 2 e3) foi retirada de uma camada de quartzito com granada e ortopiroxênio, situada na parte leste do Domínio Jequié-Mutuípe. A segunda e terceira (XJ-153 e XJ-139, Tabs. 2 e 3) foram recolhidas na "série" toleítica granulitizada do tipo arco insular, possuindo composiçōes químicas totalmente diferentes da primeira amostra. Por fim, foram retiradas mais duas amostras (M-11 e M-06, Tabs. 2 e 3) dos metabasaltos granulitizados, ricos em Fe-Ti, que por sua vez sâo quimicamente diferentes das três primeiras. Essas quatro últimas rochas se localizam na parte oeste do Domínio da Costa Atlântica.

Nas rochas granulíticas XJ-153 e XJ-139 da "serie" toleítica do tipo arco insular e nas rochas granulíticas ricas em $\mathrm{Fe}$ Ti, M-11 e M-06, do tipo basalto de paraplataforma, o estudo do coeficiente de partição $\mathrm{Fe}-\mathrm{Mg}$ entre as granadas e ortopiroxênio primários mostra que essas fases minerais alcançaram o equilíbrio quando do clímax do metamorfismo granulítico (Barbosa op. cit.). Mesmo no caso em que a granada reage parcialmente com o clinopiroxênio (amostras XJ-153 e $\mathrm{XJ}$-139) para produzir ortopiroxênio e plagioclásio de segunda geraçâo (ou por abaixamento da temperatura ou por queda de pressão), o centro dessa granada permanece em equilíbrio com o ortopiroxênio primário. O novo ortopiroxênio tem mais ou menos a mesma química que o antigo e a composição da granada, mesmo em fase de destruição, é muito pouco modificada. Também não existem grandes diferenças de composição entre as granadas desestabilizadas nessas rochas e aquelas que permanecem estáveis em outras amostras de granulitos básicos da regiāo (Barbosa op. cit.).

Para poder examinar a influência dos parâmetros de composição química de rocha total sobre os valores estimados para as pressōes, são apresentadas na tabela 3 as análises químicas e o grau de saturação em alumina dessas cinco amostras.

Observa-se que as principais diferenças químicas entre as amostras XJ-153 e XJ-139 correspondem aos teores de $\mathrm{SiO}_{2}$ e $\mathrm{CaO}$. No que concerne ao $\mathrm{CaO}$, seu teor sendo quase o dobro na amostra XJ-153 explica o aparecimento do clinopiroxênio assim como o caráter mais anortítico do plagioclásio.

As amostras M-11 e M-06 diferenciam-se quimicamente dos dois outros granulitos básicos principalmente em $\mathrm{FeO}$ e $\mathrm{TiO}_{2}$, mas mostram também diferenças significativas em $\mathrm{SiO}_{2}$ e $\mathrm{Al}_{2} \mathrm{O}_{3}$. Os altos teores de $\mathrm{CaO}$ dessas amostras também explicam o aparecimento do clinopiroxênio e a maior abundância do componente grossularia nas granadas.

A composição química da amostra de quartzito granulítico (JB-5) é muito diferente das outras amostras.

A análise dos resultados dos cálculos das pressōes de cristalização de todas essas amostras (Tab. 3) torna evidente que o método barométrico de Wood (1974) fornece resultados muito diferentes, variando de 19,6 a 5,1 kbar, isto à temperatura constante de $800^{\circ} \mathrm{C}$. Esta grande variaçâo é inaceitável, pois, 
Tabela 2 - Parâmetros utilizados nas fórmulas termodinâmicas de estimativa de pressões

\begin{tabular}{|c|c|c|c|c|c|c|c|c|c|c|c|c|c|c|c|c|c|c|c|}
\hline & \multicolumn{6}{|c|}{ Opx } & \multirow{2}{*}{\begin{tabular}{|c|}
$\mathrm{Cpx}$ \\
$\mathrm{X}_{\mathrm{CaTs}}$ \\
\end{tabular}} & \multicolumn{7}{|c|}{ Gt } & \multicolumn{2}{|c|}{ Plag } & \multirow[b]{2}{*}{$\Delta^{\circ} \mathrm{V}$} & \multirow[b]{2}{*}{$\mathrm{K}$} & \multirow[b]{2}{*}{$\mathrm{K}_{\mathrm{A}}$} \\
\hline $\begin{array}{l}\text { TIPOS DE } \\
\text { ROCHAS }\end{array}$ & $x_{\mathrm{Fe}}$ & $\underset{M g}{X^{M 1}}$ & $\mathrm{X}_{\mathrm{Mg}}^{\mathrm{M} 2}$ & $\begin{array}{r}x^{\mathrm{M} 1} \\
\mathrm{Al}\end{array}$ & ${ }^{a} E_{n}$ & ${ }^{a_{F s}}$ & & $x_{F e}$ & $\mathrm{x}_{\mathrm{Mg}}$ & $\mathrm{x}_{\mathrm{Ca}}$ & $\mathrm{Ca}^{(1)}$ & $\begin{array}{c}\gamma \\
\mathrm{Ca}^{(3)}\end{array}$ & $\mathrm{Fe}^{\gamma(3)}$ & $\begin{array}{c}\gamma_{e}^{(1)} \\
F^{(1)}\end{array}$ & $x_{A n}$ & $\begin{array}{c}\gamma \\
\mathrm{An}^{(2)}\end{array}$ & & & \\
\hline $\begin{array}{l}\text { JB-5 } \\
\text { (Quartzito com } \\
\text { granada- } \\
\text { ortopiroxênio }\end{array}$ & 0.429 & 0,480 & 0,560 & 0,134 & 0,268 & 0,220 & & 0,557 & 0,355 & 0,042 & 1,30 & 1,42 & 1,19 & 1,020 & 0,490 & 2,220 & $-0,20$ & & 0,03 \\
\hline $\begin{array}{l}\quad \text { XJ-153 } \\
\text { (Meta-basalto } \\
\text { toleftico) }\end{array}$ & 0,537 & 0,454 & 0,448 & 0,018 & 0,203 & 0,258 & 0,052 & 0,622 & 0,153 & 0,190 & 1,09 & 1,13 & 1,03 & 1,130 & 0,690 & 1,440 & $-0,18$ & 0,075 & 0,04 \\
\hline $\begin{array}{l}\quad \text { XJ-139 } \\
\text { (Metandesito } \\
\text { basáltico } \\
\text { toleftico) }\end{array}$ & 0,518 & 0,563 & 0,565 & 0,030 & 0,318 & 0,170 & & 0,636 & 0,201 & 0,130 & 1,14 & 1,19 & 1,05 & 1,080 & 0,466 & 2,270 & $-0,19$ & & 0,03 \\
\hline $\begin{array}{l}\quad \text { M-11 } \\
\text { (Metabasalto } \\
\text { rico em } \\
\text { Fe-Ti) }\end{array}$ & 0,527 & 0,458 & 0,453 & 0,018 & 0,208 & 0,261 & 0,022 & 0,634 & 0,130 & 0,209 & 1,04 & 1,08 & 1,02 & 1,146 & 0,420 & 2,449 & $-0,18$ & 0,054 & 0,04 \\
\hline $\begin{array}{l}\quad \text { M-06 } \\
\text { (Metabasalto } \\
\text { rico em } \\
\text { Fe-Ti) }\end{array}$ & 0,677 & 0,299 & 0,291 & 0,006 & 0,087 & 0,405 & 0,023 & 0,703 & 0,060 & 0,212 & 1,03 & 1,07 & 1,00 & 1,167 & 0,330 & 2,870 & $-0,18$ & 0,070 & 0,02 \\
\hline
\end{tabular}

(1) Os coeficientes de Margules utilizados săo os propostos por Wells (1979)

(2) Adotou-se a expressão de $\gamma_{\text {An }}$ proposta por Newton \& Perkins (1982)

(3) Adotou-se a expressão de $\gamma_{\mathrm{Fe}}$ e $\gamma_{\mathrm{Ca}}$ proposta por Bohlen et al. (1983)

\author{
Abreviaçóes e símbolos utilizados \\ Opx: Ortopiroxênio \\ Cpx: Clinopiroxênio \\ Gt: Granada \\ Plag: Plagioclásio

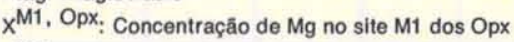 \\ $\mathrm{Mg}$

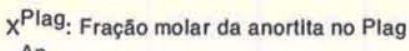

na regiâo em foco, o metamorfismo granulítico foi praticamente uniforme (Figs. 2 e 3 ).

No caso do método de Wood \& Banno (op. cit.), baseado no mesmo equilíbrio usado pelo autor anterior (reação 1), a dispersão dos resultados de pressão é igualmente considerável mas numa faixa diferente $\left(-0,4 \mathrm{a}-4,7 \mathrm{kbar}, \operatorname{com} 700^{\circ} \mathrm{C} ; 1,6\right.$ até $-3,9$ kbar com $800^{\circ} \mathrm{C}$ ). A incoerência dos resultados é aqui sublinhada pelo aparecimento de valores fortemente negativos. Ressalte-se que Ellis (op. cit.), utilizando o método de Wood \& Banno (op. cit.), encontrou igualmente valores negativos para a pressão do metamorfismo granulítico de Enderby Land, Antártica.

Observa-se também que as pressōes calculadas pelo método de Wood (1974), são correlacionadas com a concentração em alumina na posição M1 dos ortopiroxênios (Tab. 2), a qual, por sua vez, é controlada pelo grau de supersaturação em alumina na rocha (Tab. 3). Como os valores de pressấo obtidos dependem essencialmente da composição química da rocha, o barômetro de Wood (op. cit) é, por conseqüência, completamente inútil. No caso das amostras de granulitos básicos XJ-153, XJ-139, M-11 e M-06, parece existir a mesma dependência da saturação em alumina para o barômetro de Wood \& Banno (op. cit.), o que é uma razão suplementar para rejeitar igualmente este método.

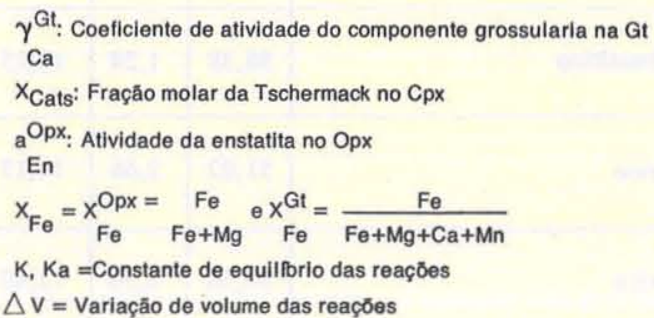

Os métodos de Wood \& Banno (1973) e Wood (1974) são igualmente muito sensíveis a um erro na avaliaçāo da temperatura, como mostra a tabela 3. Assim, qualquer incerteza na estimativa da temperatura do metamorfismo poderá produzir grandes erros na avaliação das pressōes, em valores absolutos.

Os métodos de Ellis (1980) e Bohlen et al. (1983) mostram também distorçôes nos valores de pressōes quando utilizadas rochas de composiçōes químicas diferentes ou quando se varia a temperatura do metamorfismo de $700^{\circ} \mathrm{C}$ para $800^{\circ} \mathrm{C}$ (Tab. 3 ). Ainda em relação a esses dois métodos os valores de pressão, além de dispersos, são exagerados, variando de 6 a 9 kbar (Barbosa \& Fonteilles 1986).

A tabela 3 mostra que o geobarômetro de Newton \& Perkins (1982), e principalmente o de Wells (1979), fornece resultados muito mais coerentes. Não se observam importantes variações nos valores obtidos, nem quando se muda a temperatura, nem quando se utilizam rochas de composições químicas diferentes. Também, no particular, os valores de pressẩo não são correlacionados com o teor em alumina dos ortopiroxênios em equilíbrio com as granadas.

Um fato interessante a ser observado é que a amostra de quartzito com granada e ortopiroxênio exibe valores de pressão, com temperaturas de $800^{\circ} \mathrm{C}$, mais ou menos semelhantes, seja quando se utiliza o método de Wood (1974), ou os 
Tabela 3 - Resultados de cálculos de pressão e análises químicas das amostras

\begin{tabular}{|c|c|c|c|c|c|c|c|c|c|c|c|c|}
\hline \multirow{2}{*}{ TIPOS DE ROCHAS } & \multicolumn{2}{|c|}{$\begin{array}{c}\text { Wood \& Banno } \\
\text { (1973) }\end{array}$} & \multicolumn{2}{|c|}{ Wood (1974) } & \multicolumn{2}{|c|}{ Wells (1979) } & \multicolumn{2}{|c|}{ Ellis (1980) } & \multicolumn{2}{|c|}{$\begin{array}{c}\text { Newton \& } \\
\text { Perkins (1982) }\end{array}$} & \multicolumn{2}{|c|}{$\begin{array}{l}\text { Bohlen et al. } \\
\text { (1983) }\end{array}$} \\
\hline & \multicolumn{2}{|c|}{$\begin{array}{c}\mathbf{P}(\mathrm{kbar}) \\
7^{\circ 00^{\circ} \mathrm{C}} \mathbf{8 0 0}^{\circ} \mathrm{C}\end{array}$} & \multicolumn{2}{|c|}{$\begin{array}{c}\mathbf{P}(\mathrm{kbar}) \\
700^{\circ} \mathrm{C} 80^{\circ} \mathrm{C}\end{array}$} & \multicolumn{2}{|c|}{$\begin{array}{c}\mathbf{P}(\mathrm{kbar}) \\
700^{\circ} \mathrm{C} \\
800^{\circ} \mathrm{C}\end{array}$} & \multicolumn{2}{|c|}{$\begin{array}{c}\mathbf{P}(\mathrm{kbar}) \\
700^{\circ} \mathrm{C} 80^{\circ} \mathrm{C}\end{array}$} & \multicolumn{2}{|c|}{$\begin{array}{c}\mathbf{P}(\mathrm{kbar}) \\
700^{\circ} \mathrm{C} 80^{\circ} \mathrm{C}\end{array}$} & \multicolumn{2}{|c|}{$\begin{array}{c}\text { P (kbar) } \\
700^{\circ} \mathrm{C} 800^{\circ} \mathrm{C}\end{array}$} \\
\hline $\begin{array}{l}\text { JB-5 } \\
\text { (Quartzito com granada- } \\
\text { ortopiroxênio) }\end{array}$ & $-0,4$ & 1,6 & 1,0 & 5,1 & 4,9 & 4,7 & & & 5,9 & 6,0 & 10,2 & 10,3 \\
\hline $\begin{array}{l}\text { XJ-153 } \\
\text { (Metabasalto } \\
\text { toleítico) }\end{array}$ & $-0,5$ & 1,8 & 12,5 & 18,2 & 5,6 & 5,4 & 9,0 & 8,4 & 6,0 & 6,2 & 9,8 & 9,8 \\
\hline $\begin{array}{l}\text { XJ-139 } \\
\text { (Metandesito basáltico } \\
\text { toleítico) }\end{array}$ & $-4,3$ & $-2,5$ & 9,5 & 14,8 & 4,5 & 4,3 & & & 5,3 & 5,7 & 11,0 & 11,0 \\
\hline $\begin{array}{l}\text { M-11 } \\
\text { (Metabasalto rico } \\
\text { em Fe-Ti) }\end{array}$ & $-4,6$ & $-3,8$ & 11,7 & 17,3 & 4,7 & 4,6 & 6,8 & 6,0 & 6,5 & 6,2 & 6,4 & 6,7 \\
\hline $\begin{array}{l}\text { M-06 } \\
\text { (Metabasalto rico } \\
\text { em Fe-Ti) }\end{array}$ & $-4,7$ & $-3,9$ & 13,4 & 19,6 & 4,9 & 4,0 & 8,3 & 7,7 & 6,1 & 6,0 & 7,8 & 8,0 \\
\hline \multicolumn{13}{|c|}{ ANÁLISES QUÍMICAS (ROCHA TOTAL) } \\
\hline & & $\mathrm{SiO}_{2}$ & $\mathrm{TiO}_{2}$ & $\mathbf{A l}_{2} \mathbf{O}_{3}$ & $\mathrm{FeO}$ & MnO & MgO & $\mathrm{CaO}$ & $\mathrm{Na}_{2}$ & $\mathbf{K}_{2} \mathbf{O}$ & Total & $\triangle$ \\
\hline $\begin{array}{l}\text { JB-5 } \\
\text { (Quartzito com granada- } \\
\text { ortopiroxênio) }\end{array}$ & & 87,22 & 0,26 & 4,41 & 3,41 & 0,07 & 0,51 & 0,04 & 0,47 & 1,66 & 98,05 & +35 \\
\hline $\begin{array}{l}\text { XJ-153 } \\
\text { (Metabasalto } \\
\text { toléfico) }\end{array}$ & & 50,57 & 1,04 & 16,10 & 14,06 & 0,27 & 5,79 & 10,33 & 1,36 & 0,50 & 100,02 & -107 \\
\hline $\begin{array}{l}\text { XJ-139 } \\
\text { (Metandesito basáltico } \\
\text { toleítico) }\end{array}$ & & 56,38 & 1,24 & 16,15 & 11,75 & 0,21 & 4,96 & 5,85 & 2,93 & 0,75 & 100,22 & -3 \\
\hline $\begin{array}{l}\text { M-11 } \\
\text { (Metabasalto rico } \\
\text { em Fe-Ti) }\end{array}$ & & 51,92 & 2,66 & 14,17 & 15,11 & 0,33 & 3,16 & 6,37 & 1,93 & 0,38 & 92,21 & -20 \\
\hline $\begin{array}{l}\text { M-06 } \\
\text { (Metabasalto rico } \\
\text { em Fe-Ti) }\end{array}$ & & 50,56 & 2,50 & 12,40 & 15,42 & 0,33 & 3,13 & 7,81 & 2,61 & 0,42 & 100,69 & -129 \\
\hline
\end{tabular}

$\Delta=\mathrm{Al}-\mathrm{Na}-\mathrm{K}-2 \mathrm{Ca}$ (grau de supersaturaçāo em alumina)

métodos de Wells (1979) e Newton \& Perkins (1982). Isso leva a admitir que o método de Wood (op. cit.) é inaceitável quando os ortopiroxênios apresentam teores suficientemente elevados em alumina.

Esta discussão conduz a considerar que as pressões calculadas pelos métodos de Newton \& Perkins (op. cit.) e, principalmente, pelo de Wells (op. cit.) são as mais válidas para a regiāo, embora pareçam ser ainda um pouco exageradas, como se constatará a seguir.

DISCUSSÕES E CONCLUSÕES O barômetro de Wood \& Banno (op. cit.), que dá resultados dispersos e freqüentemente negativos, e o de Wood (op. cit.), que é muito sensível à composição química das rochas e a erros de avaliação das temperaturas metamórficas, parecem inúteis. Entretanto, este último método fornece resultados aceitáveis quando aplicados em rochas portadoras de ortopiroxênios com teores suficientemente baixos em alumina.

Os barômetros de Ellis (op. cit.) e Bohlen et al. (op. cit.), apesar de apresentarem resultados mais consistentes que os anteriores, são também influenciados pelas temperaturas e, principalmente, pelas composiçōes químicas das rochas. Além disso, as pressōes estimadas são relativamente altas.
Os resultados fornecidos pelos barômetros de Newton \& Perkins (op. cit.) e de Wells (1979) são bem agrupados e, portanto, mais significativos que os anteriores. No primeiro método, as pressões se situam numa faixa de 5 a 6 kbar. No segundo, entre 4 e $5 \mathrm{kbar}$, em ambos os casos considerando $800^{\circ} \mathrm{C}$, que é a média das temperaturas da fácies granulito da regiāo.

Entretanto, como foi demonstrado por Barbosa \& Fonteilles (op. cit) no maciço de Agly, Pirineus, França, os valores de pressão obtidos por esses dois últimos métodos são ainda exagerados. Nessa regiāo da França, numa escarpa montanhosa próximo à fronteira com a Espanha, ocorre uma sucessão contínua de rochas, desde sedimentares no topo, praticamente isentas de metamorfismo, até rochas da fácies granulito, na base. Neste intervalo, localizam-se rochas da fácies xisto-verde e anfibolito. O metamorfismo é do tipo baixa pressão e se desenvolveu de modo progressivo e com forte gradiente térmico, provocando até anatexia em rochas da fácies anfibolito. Ele atingiu seu clímax após o amortecimento das principais fases de deformaação. Esses fatos indicam que o metamorfismo nessa região da França é semelhante ao encontrado no sul da Bahia.

As pressồes mais baixas encontradas em Agly, com os 
geobarômetros de Newton \& Perkins (op. cit.) e Wells (op. cit.), situaram-se em torno de 4,2 kbar. Se for considerado este valor para a pressäo do metamorfismo e se for utilizada a relação $1 \mathrm{kbar} / 3,7 \mathrm{~km}$, correspondente a uma densidade média de 2,7 para os terrenos dessa região francesa, onde as rochas ácidas predominam, deve-se admitir que durante o metamorfismo havia uma espessura litológica de no mínimo $15 \mathrm{~km}$ acima das rochas da fácies granulito. Entretanto, o gradiente metamórfico, construído a partir de dados topográficos, das isógradas e de alguns elementos termodinâmicos, mostra que na época do metamorfismo a espessura da pilha sobre as rochas granulíticas não foi maior que $8,2 \mathrm{~km}$, o que equivale a uma pressāo aproximada de $2,2 \mathrm{kbar}$, muito diferente do valor de 4,2 kbar calculado a partir dos geobarômetros mencionados.

Assim, admitindo-se como válido o exemplo de Agly, deve-se considerar como mais significativos os resultados de pressōes mais baixos. Dessa forma, para a regiāo granulítica do sul da Bahia, pode-se admitir como mais razoáveis os valores, também mais baixos, de pressão de cristalização situados em torno de 4-5 kbar e encontrados com o método de Wells (op. cit.). Vale salientar que esses baixos valores foram recentemente comprovados nas rochas kinzigíticas do Domínio Jequié-Mutuípe utilizando-se o método cordierita-plagioclásio de Newton \& Haselton (1982 e Barbosa s.d.), o que permite classificar este metamorfismo regional como do tipo baixa pressão. $\mathrm{O}$ aparecimiento de granadas sendo controlado principalmente pela composição química das rochas da região $\mathrm{e}$, a ausência de cianita nos kinzigitos (abundantes em cordierita e com raras silimanitas), também refletem as baixas pressōes que devem ter predominado durante o metamorfismo.

Diante do exposto, fica claro que, no caso dos barômetros, como eles são suspeitos de fornecerem valores mais elevados que a realidade, as pressōes por eles registradas devem ser sistematicamente confrontadas com o cojunto de dados geológicos disponíveis. Os valores estimados, se aceitos sem crítica, são frequentemente difíceis de integrar num modelo geodinâmico simples e coerente, com o risco de conduzir à criação de teorias fantasiosas.

Finalizando, no estudo dos terrenos granulíticos, nas regiōes onde se conhece a passagem para fácies de mais baixo grau, com isógradas cartografáveis, é importante se assegurar que o gradiente metamórfico, calculado por fórmulas termodinâmicas, é compatível com o estabelecido com a ajuda das isógradas. Assim, a questão da validade das pressōes obtidas para os terrenos granulíticos poderá ser mais bem esclarecida.

Agradecimentos $\mathrm{O}$ autor externa seus agradecimentos ao Professor Abílio C.S.P. Bittencourt, pela colaboração na revisão do texto; e aos professores Shiguemi Fujimori e Umberto Costa, pela valiosa ajuda nas discussōes e sugestōes sobre o tema.

\section{REFERÊNCIAS BIBLIOGRÁFICAS}

BARBOSA, J.F. \& FONTEILLES, M. 1986. Examen critique des résultats fournis par certains baromètre couramment utilisés en terrains granulitiques. Exemples des granulites de Bahia-Brésil et du Massyf de Agly (France). Bull. Mineral., 109:359-376.

BARBOSA, J.F. 1986. Constitution lithologique et metamorphique de la Région Granulitique de Sud de Bahia, Brésil (Tese de Doutoramento, Universidade Paris VI, no ordem 86-64)

BARBOSA, J.F. (s.d.) Geobarometria das rochas kinzigiticas da região de Mutuípe, Bahia (em elaboração)

BOHLEN, S.R.; WALL, J.J.; BOETTCHER, A.L. 1983. Geobarometry in granulites. In: SAXENA, S.K. ed. Kinetics and equilibrium in mineral reactions. Springer-Verlag.

CORDANI, U.G. 1973. Evolução geológica Pré-Cambriana da faixa costeira do Brasil, entre Salvador e Vitória. São Paulo, Int. Geoc. USP. (Tese de Livre-Docência, USP)

ELLIS, D.J. 1980. Osumilite-saphirine-quartz granulites from Enderby Land, Antarctica: P-T conditions of metamorphisms, implications for garnet-cordierite equilibria and the evolution of deep crust. Contrib. Mineral. Petrol., 74:210-210.

ESSENE, E.J. 1983. Geologic thermometer and barometer. Springer-Verlag. 320p.

MASCARENHAS, J.F. 1973. A geologia do centro-leste do Estado da Bahia. In: CONGR. BRAS. GEOL., 28, Aracaju, 1973. Anais... Aracaju, v. 2, p. 35-66. (Simp. sobre o Pré-cambriano do Cráton São Francisco e da parte norte-oriental do Brasil)

MASCARENHAS, J.F. 1979. Evolução Geotectônica do Précambriano do Estado da Bahia. In: GEOL. E REC. MIN. DO ESTADO DA BAHIA, Textos Básicos, Salvador SME/CPM, 57-165.

NEWTON, R.C. \& PERKINS, D. III. 1982. Thermodynamic calibration of geobarometer based on the assemblages garnetplagioclase-orthopiroxene (clinopyroxene)-quartz. Am. Miner., 67:203-222.
PEDREIRA, A.J. 1975. Projeto Bahia II. Geologia da Bacia do Rio de Contas. Salvador, DNPM/CPRM, 250p.

SUBRAMANIAN, A.P. 1967. Charnokites and granulites of Southern India. Maddeleiser fra Dansk Geologisk Forening, 17:4-20.

TONIATTI, G. \& BARBOSA, J.F. 1973. O manganês de Maraú-Bahia, Avaliação de Reservas. In: CONGR. BRAS. GEOL., 27, Sergipe, 1973. Anais... Sergipe, SBG. v.2, p. 413-421.

VALARELLI, J.V.; BARBOSA, J.F.; HYPOLITO, J.R.; SILVEIRA BELLO, R.M. 1982. Paragênese do protominério metamórfico de manganês de Maraú, Bahia. In: CONGR. BRAS. GEOL., 32, Anais... Salvador, SBG, v.3, p. 819-835.

WANG, KAIYI, YAN YUEHUA; YANG RUIYING; CHEN YIFEI. 1985. REE geochemistry of early precambrian charnokites and tonalitic-granodioritic gneisses of the Qianan Region, Eastern Hebei, North China. Precambr. Research., 27:63-84.

WEAVER, B.L.; TARNEY, J.; WINDLEY, B.F.; SUGAVANIAN, E.B.; VENKATA RAÖ, V. 1978. Madras granulites. Geochemistry and P.T. conditions of crystalization. In: Windley, Po. F. \& Navqvi, A. Eds. Archaean Geochemistry.

WELLS, P.R.A. 1977. Pyroxene termometry in simple and complex systems. Contrib. Mineral. Petrol., 62:129-139.

WELLS, P.R.A. 1979. Chemical and thermal evolution of Archaean sialic crust, southern west Greenland. J. Petrol., 20:187-226.

WOOD, B.J. \& BANNO, S. 1973. Garnet-orthopyroxene and orthopyroxene-clinopyroxene relationship in simple and complex systems. Contrib. Mineral. Petrol., 42:109-124.

WOOD, B.J. 1974. The solubility of alumina in orthopyroxene coexisting with garnet. Contrib. Mineral. Petrol., 46:1-15

MANUSCRITO 520

Recebido em 29 de janeiro de 1988 Revisão aceita em 10 de abril de 1988 